\title{
ALFABETIZAÇÃO E AFRICANIDADES: EXPERIÊNCIAS FORMATIVAS NO CURSO DE EXTENSÃO LER E ESCREVER NA ESCOLA
}

\author{
ALFABETIZACIÓN Y AFRICANIDADES: EXPERIENCIAS FORMATIVAS EN \\ EL CURSO DE EXTENSIÓN LEER Y ESCRIBIR EN LA ESCUELA
}

\section{LITERACY AND AFRICANITIES: TRAINING EXPERIENCES IN THE EXTENSION COURSE READ AND WRITE IN SCHOOL}

Luciene CERDAS ${ }^{1}$

Rejane AMORIM ${ }^{2}$

RESUMO: Esse artigo apresenta uma prática formativa de professores alfabetizadores no "Curso de Extensão ler e escrever: articulando saberes, construindo práticas", realizada a partir de um tema que vem ganhando cada vez mais destaque na área da educação, a saber, as Africanidades, dando ênfase às marcas da cultura africana na construção da cultura brasileira. Socializa-se o potencial dessa ação na formação de professores alfabetizadores e de licenciandos em Pedagogia, que atuam como parte da equipe de execução do curso. Uma vez na semana, estudantes e docentes da Pedagogia e professores das escolas públicas do Rio de Janeiro se reúnem a fim de discutir questões relacionadas à docência na alfabetização, leitura e escrita e à construção de práticas inovadoras em alfabetização, de tal modo que a formação inicial e continuada de professores seja construída em diálogo com esses sujeitos. O tema "Africanidades" foi abordado na perspectiva da valorização das raízes da cultura brasileira de origem africana, discutindo-se as relações étnico-raciais, as concepções relativas aos preconceitos raciais, em nome do urgente e necessário respeito aos diferentes modos de ser, de viver e conviver. Destaca-se, assim, uma experiência promissora de trabalho com essa temática a partir de duas propostas distintas: construção do Panõ Africano e Confecção da Boneca Abayomi, atividades que envolveram diferentes linguagens, tais como leitura, desenho, pintura e artesanato. Essas ações demonstraram grande potencial formativo na perspectiva de alfabetização em que a integração curricular, bem como a linguagem como interação humana são pressupostos centrais

PALAVRAS-CHAVE: Alfabetização. Ensino de leitura e escrita. Africanidades. Formação de professores.

RESUMEN: Este artículo presenta una práctica formativa de profesores alfabetizadores en "Curso de Extensión leer y escribir: articulando saberes,

${ }^{1}$ Universidade Federal do Rio de Janeiro (UFRJ), Rio de Janeiro - RJ - Brasil. Professora Adjunta do Departamento de Didática da Faculdade de Educação. ORCID: <http://orcid.org/0000-0001-6967-0692>. E-mail: lucienecerdas@hotmail.com

${ }^{2}$ Universidade Federal do Rio de Janeiro (UFRJ), Rio de Janeiro - RJ - Brasil. Professora Adjunta do Departamento de Didática da Faculdade de Educação. ORCID: <http://orcid.org/0000-0003-3683-4026>. E-mail: rejane.amorim@ufrj.br 
construyendo prácticas", que se realizó a partir de un tema que viene destacándose cada vez más en los estudios de educación, a saber, las Africanidades, con énfasis a las marcas de cultura africana en la construcción de la cultura brasileña. Se socializa el potencial de esa acción en la formación de profesores alfabetizadores y de licenciandos en Pedagogía que actúan como parte del equipo de ejecución del curso. Una vez por semana, estudiantes y docentes de Pedagogía y profesores de las escuelas públicas de Rio de Janeiro se reúnen para discutir cuestiones relativas a la docencia en alfabetización, lectura y escritura, y la construcción de prácticas innovadoras en alfabetización, de modo que la formación inicial y continuada de profesores sea construida en diálogo con esos sujetos. El tema de las Africanidades fue abordado en la perspectiva de valoración de las raíces de la cultura brasileña que tienen origen africano, discutiendo las relaciones étnico-raciales, las concepciones relativas a los prejuicios raciales, en nombre del urgente y necesario respeto a los diferentes modo de ser, vivir y convivir. Se destaca, así, una experiencia prometedora de trabajo con esa temática a partir de dos propuestas distintas: construcción del Panõ Africano y Confección de la Muñeca Abayomi, actividades que involucraron diferentes lenguajes, tales como la lectura, el dibujo, la pintura y la artesanía. Estas acciones demostraron gran potencial formativo en la perspectiva de la alfabetización en que la integración curricular así como el lenguaje como interacción humana son presupuestos centrales.

PALABRAS CLAVE: Alfabetización. Enseñanza de lectura y escritura. Africanidades. Formación de profesores.

ABSTRACT: This article presents a training practice of literacy teachers in the "Extension Course read and writing: articulating knowledge, building practices", carried out from a theme that has been gaining increasing prominence in the education area, namely, Africanities, which emphasizing the marks of African culture in the construction of Brazilian culture. The potential of this action is socialized in the formation of literacy teachers and of graduates in Pedagogy who act as part of the course implementation team. Weekly, It brings together students and teachers from Pedagogy and public school teachers in Rio de Janeiro to discuss issues related to teaching in literacy, reading and writing, and to the construction of innovative practices in literacy, in such a way that initial and teachee's formation built in dialogue with these subjects. The subject of Africanities was approached from the perspective of the valorization of the roots of Brazilian culture that are of African origin, discussing ethnic-racial relations, conceptions of racial prejudices, in the name of the urgent and necessary respect for the different ways of being, of living and living together. A promising experience of working with this theme is based on two different proposals: the construction of the African Pano and the making of the Abayomi doll, activities that have ivolved different languages, such as reading, drawing, painting and handicrafts. These actions demonstrated great training potential in the perspective of literacy in which curriculum integration as well as language as human interaction, are central assumptions.

KEYWORDS: Literacy. Teaching of reading and writing. Africanities. Teacher training. 


\section{Introdução}

Neste artigo trazemos uma discussão sobre a formação inicial e continuada de alfabetizadores, a partir das contribuições da ação extensionista "Curso de Extensão ler e escrever: articulando saberes, construindo práticas" - que se inscreve no âmbito do grupo de pesquisa do qual fazemos parte e que tem se dedicado a ações de ensino, pesquisa e extensão no âmbito da Faculdade de Educação. Destacamos uma experiência promissora de trabalho e integração entre a área de linguagem e ciências humanas, cujo tema "Africanidades" foi desenvolvido a partir de duas atividades distintas: Construção do Panõ Africano e confecção da Boneca Abayomi, que envolveram o trabalho com diferentes linguagens, tais como leitura, desenho, pintura e artesanato, além da oralidade, a partir dos diálogos realizados, bem como a socialização dos trabalhos produzidos e a expressão dos sujeitos sobre suas aprendizagens.

A primeira turma iniciou o curso em setembro de 2016 e o concluiu em junho de 2017, contemplando 30 horas, que foram distribuídas em 15 encontros quinzenais de duas horas que aconteceram na Faculdade de Educação, congregando professores da rede pública de ensino do Rio de Janeiro, docentes do curso de Pedagogia coordenadoras do curso - e estudantes de Pedagogia e de outras licenciaturas. Vale destacar que, nesse curso, nos empenhamos para que esses diferentes sujeitos construíssem em diálogo saberes e práticas para o ensino da leitura e da escrita. São, portanto, todos protagonistas da sua formação e da construção de práticas inovadoras em alfabetização.

As abordagens feitas durante o curso enfatizaram questões relacionadas ao ler e escrever na escola, com as seguintes temáticas: Práticas iniciais de alfabetização: uso do nome; Trabalho com Sequências Didáticas utilizando gêneros textuais (Oralidade, leitura, escrita): cartas, bilhetes, listas, receitas, trava-línguas; Projeto interdisciplinar utilizando a literatura infantil: Autores - Ruth Rocha, Ana Maria Machado, Ziraldo, Cecília Meireles; O lúdico na alfabetização: Oficina de Massinha "Trucks"; Jogos na alfabetização; Alfabetização Matemática e a resolução de problemas: trabalhando conceitos; A escrita na Alfabetização e Africanidades.

Entre outras contribuições, esse curso tem demonstrado marcas positivas no processo formativo de todos os envolvidos. Para os inscritos no curso, as avaliações realizadas sobre os encontros deixam entrever impactos na sua formação continuada, uma vez que consideram muito positivas as temáticas abordadas e as dinâmicas 
vivenciadas na construção de experiências teórico práticas em alfabetização. O curso também tem permitido a nós, professoras da Faculdade de Educação, ampliar as discussões sobre formação de professores, tanto no aprofundamento teórico do tema quanto na busca de práticas efetivas de formação docente para o ensino da leitura escrita. Em relação aos estudantes da Pedagogia, que atuam na execução do curso, seus relatórios de aprendizagens revelam uma profícua reflexão sobre a prática de alfabetização e a construção de referenciais para o ensino da leitura e escrita.

Outro destaque que vale considerar é a dinâmica dos encontros, que são organizados de forma que todos participem na criação, desenvolvimento e produção de atividades dentro da temática proposta. Assim, realmente tenham a experiência, na perspectiva de Larrosa (2002), para quem o saber da experiência se dá na relação entre o conhecimento e a vida humana.

Finalmente, a escolha por relatar a experiência vivenciada com a temática das Africanidades deve-se a sua importância na educação das crianças, desde o início de sua escolarização, no reconhecimento de sua identidade como parte de uma cultura, esta constituída por diferentes raízes - africanas, indígenas e europeias, para dar alguns exemplos - e que estão presentes no nosso dia a dia, seja na língua, no vestuário, na comida, nas brincadeiras, na música, entre outros aspectos que compõem o rico repertório cultural brasileiro.

\section{Africanidades: uma proposta de trabalho na integração dos saberes das Ciências Humanas e Linguagem}

Entendemos que a alfabetização, desde suas fases iniciais, se dá pelo desenvolvimento de saberes fundamentais no processo de inserção dos sujeitos nas práticas sociais de uso da língua em um contexto permeado pela escrita, o qual não está apartado dos conteúdos das diversas componentes curriculares. Não se alfabetiza com textos para ensinar ler e escrever, mas com textos do cotidiano e que falam de assuntos do cotidiano. A apropriação desses conhecimentos, em especial da linguagem, é que "[...] possibilita ao sujeito existir, interagir e refletir, materializando suas experiências, sendo concebida como algo que organiza e tensiona a vida coletiva e individual, dado que organiza aquelas experiências." (GOULART; GONÇALVES, 2013, p. 21).

Se pensarmos a alfabetização a partir da concepção que defendemos, como conhecimento de mundo (FREIRE, 1996), a leitura da palavra e do mundo são um 
amálgama muito forte, impossível de ser separado. Portanto, não é preciso primeiro aprender a ler, escrever e contar para só então aprender os conhecimentos da história e da geografia, das ciências, das artes... Estes são necessários no percurso de seu desenvolvimento e podem ser mobilizados por meio de uma diversidade de estratégias metodológicas.

No Ciclo de Alfabetização, por exemplo, as Ciências Humanas estão representadas pelo ensino da História e da Geografia que, ao dialogarem com conceitos de outras ciências, ampliam a compreensão das crianças sobre o mundo social. Esses conhecimentos nem sempre têm lugar nas práticas alfabetizadoras nos anos iniciais do Ensino Fundamental, embora entendamos que o desenvolvimento da leitura, escrita, oralidade e análise linguística, como eixos da alfabetização, deva se dar a partir da articulação da linguagem com as diversas áreas do currículo. Os problemas do cotidiano não se explicam a partir de um único ponto de vista, o que impossibilita uma compreensão da realidade para além de seus aspectos isolados.

Só podemos conhecer o objeto de estudo em sua totalidade, se consideramos que a multiplicidade de olhares possíveis é que permite a ampliação do entendimento de mundo pelos sujeitos, no caso as crianças, que nesse momento mergulham no universo da linguagem escrita. Ao dar continuidade a seu processo de aprendizagem acerca da língua escrita, iniciado bem antes de adentrar às salas de aula, mas agora de modo mais sistemático, as crianças deverão ter acesso aos diferentes saberes que permitem a elas dar sentido ao mundo a sua volta a partir da apropriação das diferentes linguagens que as cercam.

A perspectiva integradora, aqui defendida, tem como propósito que a prática pedagógica do alfabetizador se construa a partir do entendimento de que é possível a articulação das diferentes áreas nos processos de ensino aprendizagem, em especial àqueles concernentes à inserção das crianças na cultura escrita. Ela pode se dar na proposição de projetos didáticos de estudo de temas específicos propostos pelas próprias crianças ou pelos professores, tais como o da Africanidades, aqui abordado. Um tema que vem ganhando cada vez mais destaque na área da educação, dando ênfase às marcas da cultura africana na construção da cultura brasileira. Foi abordado na perspectiva da valorização das raízes da cultura brasileira, que têm origem africana, discutindo-se as relações étnico-raciais, as concepções relativas aos preconceitos raciais em nome do urgente e necessário respeito aos diferentes modos de ser, de viver e conviver. 
O trabalho que relatamos aqui foi realizado no curso de extensão composto por um contingente significativo de afrodescendentes, que corresponde à população carioca. De acordo com o senso de 2010, o percentual de pessoas que se declararam negras e pardas corresponde a mais de 50\% da população. (Censo Demográfico IBGE, 2010).

Como coordenadoras do curso, a experiência de trabalho com essa temática fez emergir histórias de marginalização e preconceitos que marcaram e marcam a vida desses professores e alunos que participaram do curso. Histórias que também eles vivenciam em sala de aula com seus alunos, de maioria negra.

Tal como aponta Silva (2003, p. 26), estudar essas Africanidades Brasileiras é mais do que conhecer um evento material (pratos típicos, um ritmo), implica conhecer um "[...] jeito de ver a vida, o mundo, o trabalho, de conviver e lutar por sua dignidade, próprio dos descendentes de africanos [...] vão deixando nos outros grupos étnicos com que convivem suas influências, e, ao mesmo tempo, recebem e incorporam as daqueles."

Embora nossa motivação para esse trabalho não seja meramente legal, mas ideológica e ética, não podemos deixar de apontar que ensinar História e Cultura Afrobrasileiras e Africanas é uma questão curricular de caráter obrigatório que envolve as diferentes comunidades: escolar, familiar, e sociedade. O objetivo principal para inserção da Lei 10639/03 - atualizada pela lei 11.645/2008 que insere a questão indígena - visa fazer um resgate histórico para que as pessoas negras afro-brasileiras conheçam um pouco mais o Brasil e melhor a sua própria história. Compreender a pluralidade étnico-racial nos capacita a interagir, respeitar e valorizar a identidade cultural brasileira e africana, como outras que direta ou indiretamente contribuíram (contribuem) para a formação da identidade cultural brasileira.

Infelizmente, a temática nem sempre é abordada nas escolas, no sentido do questionamento do racismo, dos estereótipos e preconceitos que caracterizam a sociedade brasileira, a partir de um projeto de educação intercultural em que, como explicam Silva (2016), deve-se respeitar as sociodiversidades a partir da construção de espaços de questionamento, levando em conta os processos históricos e relações de poder que ocorrem nas sociedades, promovendo relações que favoreçam a convivência respeitosa e o diálogo intercultural.

Os autores, no entanto, apontam como desafios a esse projeto a falta de qualificação dos profissionais sobre as questões étnico-raciais; ausência de subsídios pedagógicos; a naturalização do racismo, mesmo institucional "[...] quando gestores/as, 
professores/as e demais profissionais que atuam no ensino de formas sutis ou mesmo clara explicitam cotidianamente seus preconceitos étnico-raciais, ao silenciarem, ou se negarem ou não favorecerem tratar dessas temáticas no espaço escolar." (SILVA, 2016, p. 79).

Concordamos com Silva (2003, p.28) que as Africanidades não precisam constituir-se numa única área, mas podem estar presentes nas diferentes áreas de conhecimento do currículo escolar, conduzindo a uma pedagogia antirracista, cujos princípios são:

- respeito, entendido não como mera tolerância, mas como diálogo em que seres humanos diferentes miram-se uns aos outros, sem sentimentos de superioridade ou de inferioridade;

- reconstrução do discurso pedagógico, no sentido de que a escola venha a participar do processo de resistência dos grupos e classes postos à margem, bem como contribuir para a afirmação da sua identidade e da sua cidadania;

- estudo da recriação das diferentes raízes da cultura brasileira, que nos encontros e desencontros de umas com as outras se fizeram e hoje não são mais gêge, nagô, bantu, portuguesa, japonesa, italiana, alemã, mas brasileira de origem africana, européia, asiática.

Além disso, compreendemos que nossas pequenas histórias tecem a grande História e é nessa reconfiguração que ocorre uma abertura para possíveis histórias de pessoas outrora não narráveis. Dessa maneira, nosso trabalho com as Africanidades não se restringiu a uma narrativa, a uma atividade estanque, mas deu vida à materialidade da História como garantia de desvelamento de um real.

\section{A prática formativa: Africanidades}

O dia de trabalho iniciou com a leitura da história do livro Bruna e a Galinha de Angola (Figura1), de autoria de Gercilga de Almeida com ilustrações de Valéria Saraiva. Esse livro narra a história de uma menina de origem africana, que descobre no quintal de sua casa um tesouro, panõs africanos de sua avó, que narram histórias, como a lenda africana de criação do mundo. Encantada com esses panõs, identifica-se como pertencente à cultura de seus antepassados e reconhece nesse tesouro a possibilidade de maior integração com sua comunidade, na medida em que ao mostrá-los para as colegas, pode contar sua história pregressa a partir da criação de novos de panõs. 
Figura 1: Representação Bruna e a Galinha D’Angola

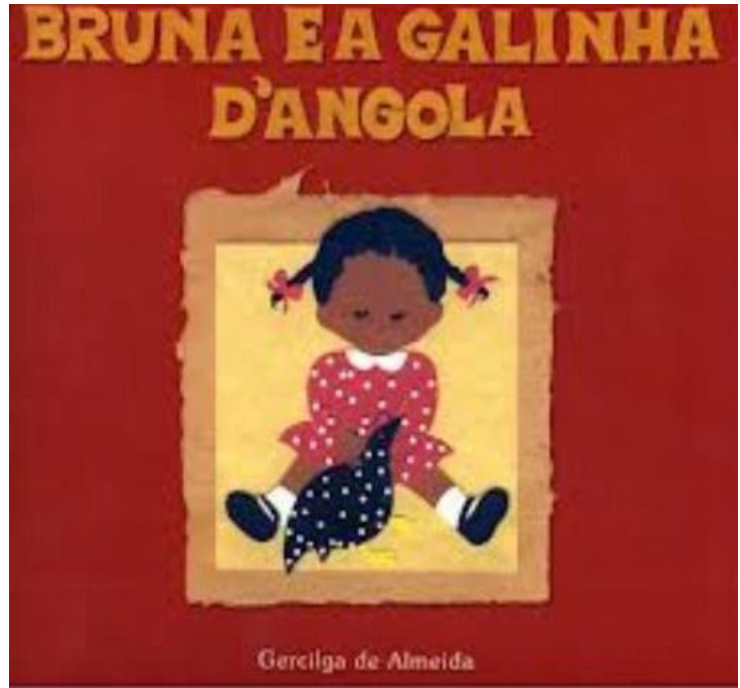

Fonte: arquivo das autoras

A partir da mobilização pela literatura e discussão sobre os sentidos do texto, foi possível criar com os professores e alunos cursistas uma rede de diálogo do qual emergiram histórias de preconceito, racismo, desigualdades sociais, mas também identidade e cultura.

Tomemos aqui a cultura representada pelo conjunto dos sentidos e significados atribuídos pelas pessoas às suas práticas sociais no processo histórico. Portanto, temos que denominar culturas, no plural, para assim podermos revelar o conjunto de significados e diferenças sociais que coexistem.

Após essa discussão, cada cursista foi convidado a pintar o seu panõ, narrando em forma de desenho lembranças vividas que marcaram sua existência (Figura 2). Para tanto, foram disponibilizados tecidos e tintas para que pudessem realizar a atividade. Nesse trabalho, a partir do uso de outras linguagens, fica aberta a possibilidade de criação e longe do código, podemos refletir sobre a pré-história da linguagem escrita (VYGOTSKY, 1988), que tem no desenho o início do processo de representação tão significativo para o percurso do alfabetizando. Utilizar diferentes linguagens com alunos alfabetizados ou não possibilita a eles o reconhecimento da possibilidade de expressão para além da escrita.

Terminada a confecção individual dos panõs, foi solicitado que cada um dos cursistas contasse a história representada, possibilitando a criação do texto oral que evidenciou diferentes percursos, lembranças e formas de viver que caracterizam a cada um de nós e que marcam o momento presente que encontramos na sala. E finalmente, 
foi confeccionada um grande panõ, com todas as produções do grupo. Destacamos a importância de não fazermos intervenções reflexivas a todo momento, pois o processo de humanização pelo qual estamos expostos durante toda vida (FREIRE, 1996; CHARLOT, 2002), nos possibilita sermos subjetivos dentro de uma realidade compartilhada, coletiva. É no processo de humanização, socialização e singularização, que o sujeito se apropria de uma parte do patrimônio humano e social construído pelas gerações anteriores e o investe numa história singular. (CHARLOT, 2000).

Além disso, não podemos esquecer que a oralidade é parte fundamental do processo de alfabetização, muitas vezes relegada a segundo plano nas práticas de ensino. Para alunos em processo de alfabetização a possibilidade de dizer implica entender, na perspectiva bakhtiniana que "Cada ato de fala não é só produto do que é dado, sempre cria algo novo que nunca existiu antes, algo absolutamente novo e não repetitivo que se revela na entonação" refletindo a diversidade da experiência social (JOBIM e SOUZA, 2012, p. 95).

Fonte: arquivo das autoras

Figura 2: Experiência social

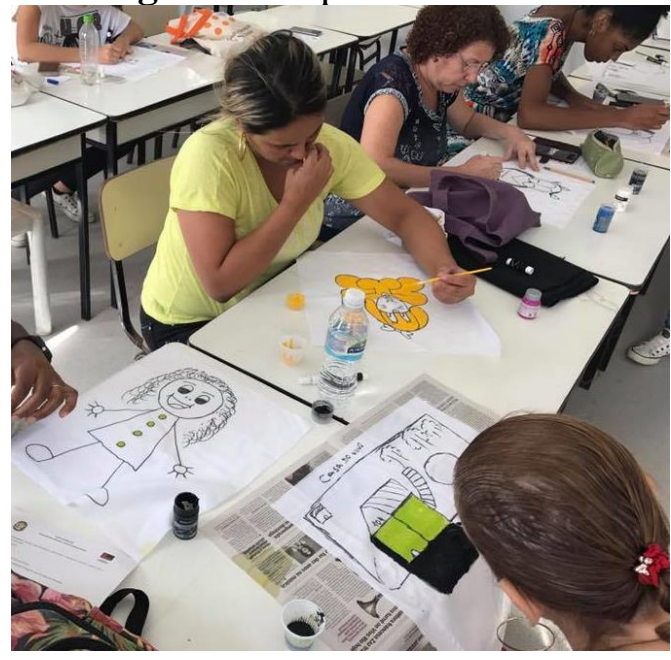

Um outro momento do trabalho com as Africanidades diz respeito à confecção da boneca africana Abayomi, que significa 'Encontro precioso', em Iorubá, uma das maiores etnias do continente africano cuja população habita parte da Nigéria, Benin, Togo e Costa do Marfim. Mais do que uma simples boneca, símbolo de resistência, ela representa a história de dominação dos povos africanos escravos, que atravessaram o Oceano Atlântico sob condições desumanas. Como as crianças choravam assustadas, porque viam a dor e o desespero dos adultos, as mães negras para acalentá-las, rasgavam retalhos de suas saias e a partir deles criavam pequenas bonecas, feitas de 
tranças ou nós, para as crianças brincarem, além de servirem como amuleto de proteção ${ }^{3}$. Duas curiosidades sobre essa boneca são importantes destacar aqui, primeiro que a boneca de pano não possui marcação de olhos, boca e nariz, assim com a cor de sua pele é capaz de representar todos os povos africanos. A segunda é a questão do gênero, já que Abayomi pode ser tanto nome de menino, quanto de menina.

A partir da apresentação da história da Abayomi, realizamos com os cursistas uma oficina para sua confecção usando tirar de pano preto e retalhos coloridos para servir como vestimenta da boneca (Figuras 3, 4 e 5). Essa atividade foi, sem dúvida, um momento de grande envolvimento afetivo dos participantes, de troca entre os pares e de dedicação a sua confecção. Entre os objetivos propostos nesse tipo de tarefa destacamos a possibilidade de refletir sobre a situação de exploração do trabalho escravo dos povos africanos na história do Brasil e sua condição atual na sociedade; desenvolver a expressão artística e criativa e a cooperação; conhecer e reconhecer Abayomi como símbolo da cultura africana.

Figura 3: Bonecas

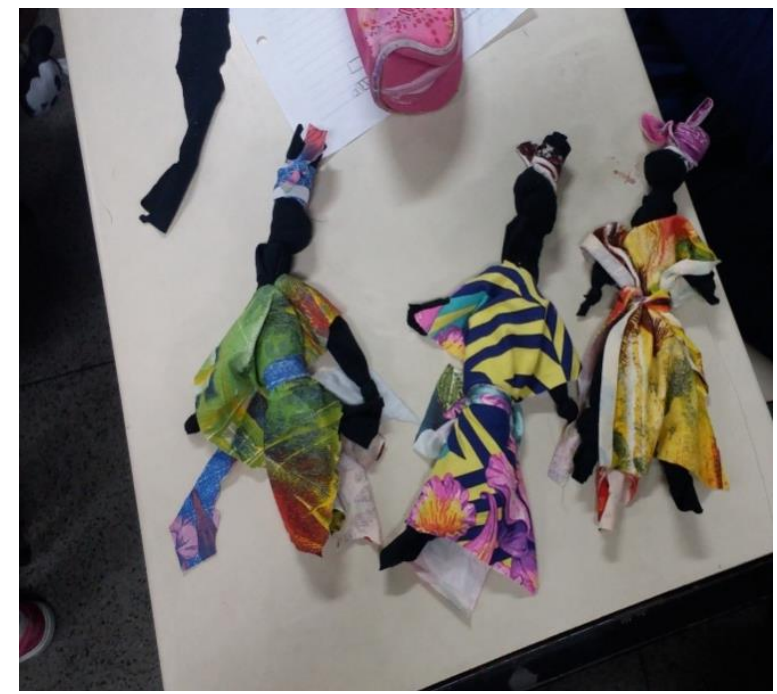

Fonte: arquivo das autoras

${ }^{3}$ Disponível em: <http://www.afreaka.com.br/notas/bonecas-abayomi-simbolo-de-resistencia-tradicao-epoder-feminino/>. Acesso em: 10 jun. 2017. 
Figura 4: Bonecas - vestimentas

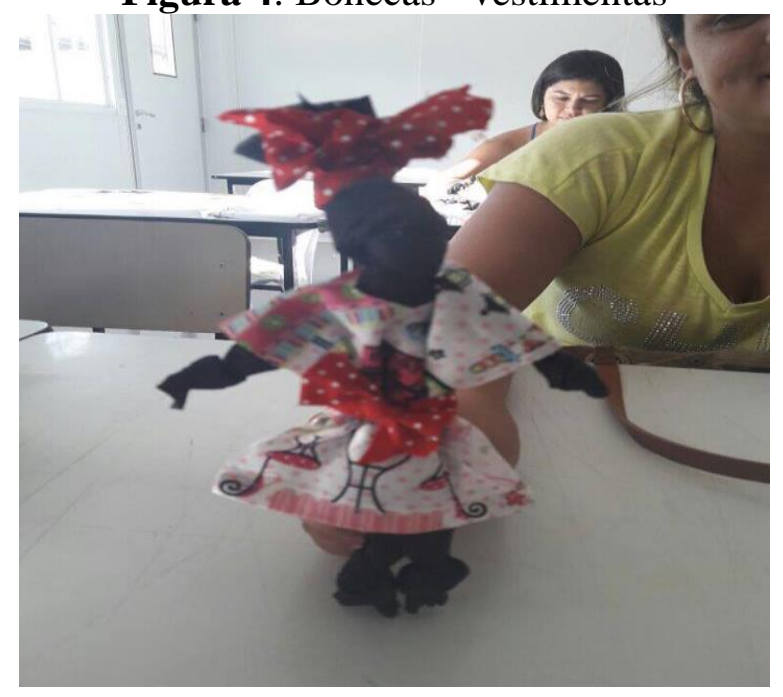

Fonte: arquivo das autoras

É interessante destacar que essa mesma oficina foi realizada por nós em um grupo de estudantes de nono ano do ensino fundamental de uma escola pública do Rio de Janeiro e em uma sala de segundo ano, com crianças em processo de alfabetização, durante uma regência de aula de uma estudante da disciplina Prática de Ensino e Estágio Supervisionado. Nas duas experiências, foi possível verificar a potencialidade criadora da atividade e o envolvimento das crianças e adolescentes, majoritariamente negros, e sua identificação com a boneca, com a qual estabeleceram um vínculo afetivo, revelado em suas atitudes e falas durante a oficina.

Isso se deve também ao fato de que a atividade, permite que cada sujeito desenvolva seu trabalho de forma subjetiva. A escolha da roupa, do cabelo, dos adereços da boneca acessou essa zona subjetiva que em tudo feito por nós se expressa. Estudantes que nem sempre apresentam trabalhos destaques na sala de aula, podem, em atividades como essa, descobrir um potencial criador, que contribuirá com seu processo de afirmação criadora no espaço educacional. 
Figura 5: Apresentação das bonecas

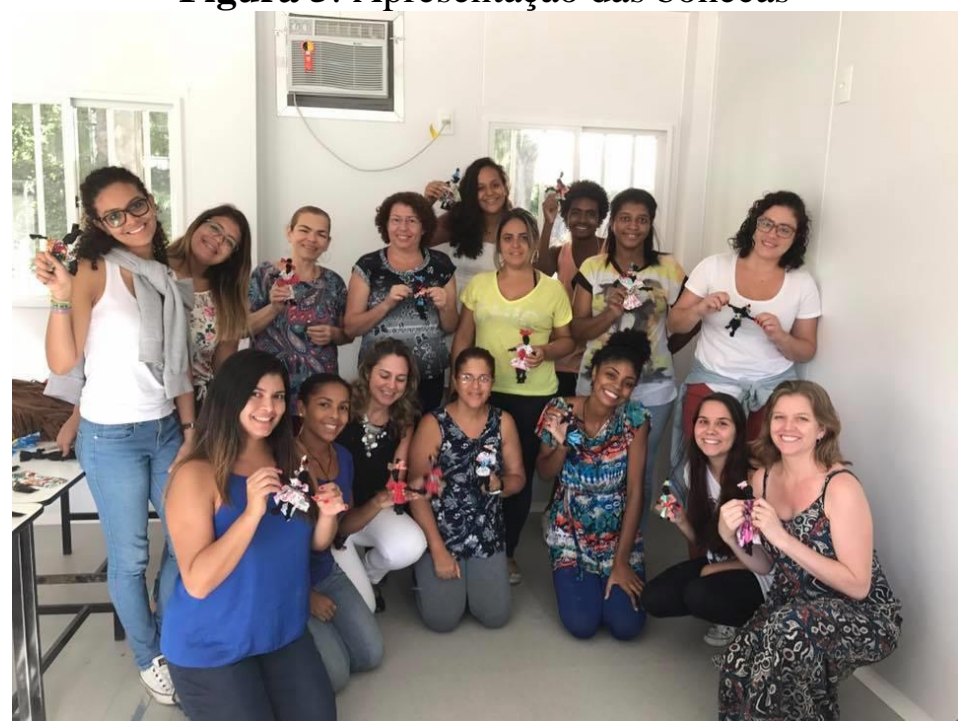

Fonte: arquivo das autoras

No final da atividade houve um movimento muito interessante entre os cursistas que iniciaram, por contra própria, uma oficina de turbantes (Figura 6), na qual uns demonstravam aos outros, diferentes amarrações possíveis feitas com variados tipos de tecido. Essa iniciativa dos estudantes e cursistas aponta o necessário reconhecimento das suas próprias identidades e a pertinência do tema na formação docente, seja a inicial ou na continuada. Essa experiência que nos toca (LARROSA, 2002) torna-se parte de nós, vai conosco para a nossa vida, e acreditamos poderá dar frutos de uma prática pedagógica mais justa, democrática em que a diversidade seja respeitada e valorizada como essência de nossa sociedade.

Figura 6: Oficina de turbantes

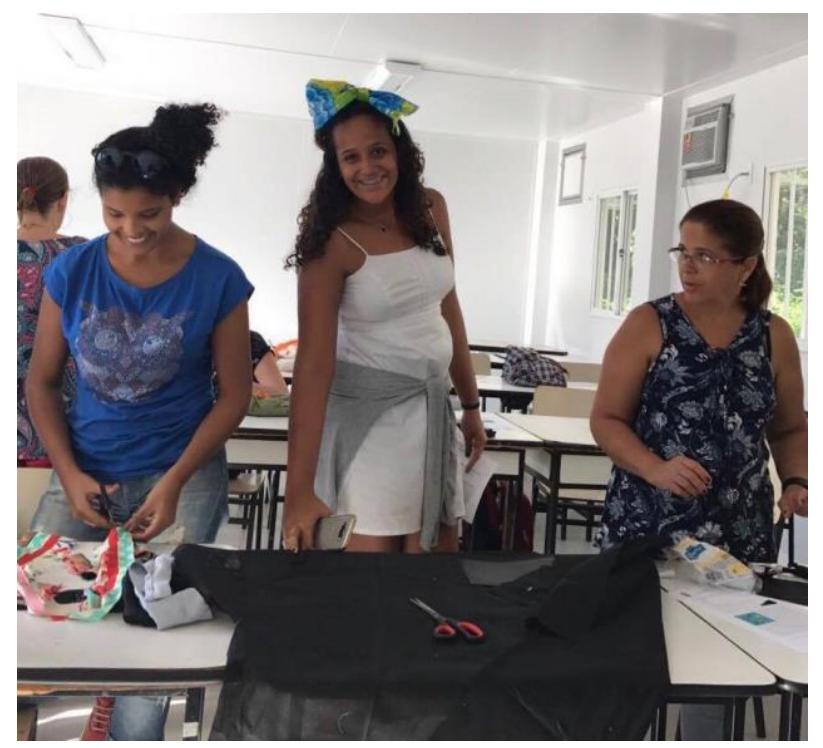

Fonte: arquivo das autoras 


\section{Considerações finais}

Avaliamos que as experiências vivenciadas nessas duas propostas apresentadas no artigo mostraram-se bastante profícuas no trabalho com a temática das Africanidades, tanto para os cursistas como para as crianças - no caso da boneca Abayomi -, de tal modo que, ao fazerem suas avaliações sobre o curso, essa vivência teve um destaque especial entre eles, como o apresentado por uma das cursistas:

No decorrer do curso, foi sendo apresentadas temáticas dinâmicas e atividades propostas que realmente me surpreenderam e porque não dizer que em certos momentos mexeram comigo, como por exemplo, a pintura em tecido, me atingiram positivamente. (Relato de Cursista)

No intuito de propor discussões sobre o tema da cultura afro-brasileira e africana na alfabetização, compreendemos que devemos ser uma força para que possamos garantir o direito a uma alfabetização desvinculada da perspectiva técnica, mas que abra espaço para a humanização no reconhecimento de nossas origens e nossas diferenças. Sintetiza nossa concepção a afirmativa de Santos (2006, p.462):

[...] temos o direito a ser iguais quando a nossa diferença nos inferioriza; e temos o direito a ser diferentes quando a nossa igualdade nos descaracteriza. Daí a necessidade de uma igualdade que reconheça as diferenças e de uma diferença que não produza, alimente ou reproduza as desigualdades.

A alfabetização necessita ser pensada de forma ampla, em que possamos reconhecer as produções culturais dentro do contexto de suas práticas, muitas vezes esvaziadas de sentido e pouco articuladas com o conhecimento de mundo. Investimos em uma formação de professores, como nesse caso, inicial e continuada, que possibilite experiências concretas e contato real com diferentes linguagens, para que a partir da vivência possam refletir sobre sua práxis em sala de aula.

\section{REFERÊNCIAS}

CHARLOT, B. Da relação com o saber: elementos para uma teoria. Porto Alegre: Artmed, 2000.

CHARLOT, B. Relação com a escola e o saber nos bairros populares. Revista Perspectiva, v. 20, n. especial, jul./dez., 2002.

FREIRE, P. Pedagogia da autonomia: saberes necessários à prática educativa. São Paulo: Paz e Terra, 1996. 
GOULART, Cecília.; GONÇALVES, Angela Vidal. Aspectos semióticos da aprendizagem inicial da escrita. In: GOULART, C. M. A.; WILSON, V. (orgs.). Aprender a escrita, aprender com a escrita. São Paulo: Summus, 2013, p. 22-42.

IBGE. Censo Demográfico 2010 - Características Gerais da População. Resultados da Amostra. Disponível em: <http://www.censo2010.ibge.gov.br>. Acesso em: 23 de out. de 2017.

JOBIM e SOUZA, S. Infância e Linguagem: Bakhtin, Vygotsky e Benjamin. Campinas/SP: Papirus, 2012.

LARROSA, J. Notas sobre a experiência e o saber de experiência. Revista Brasileira de Educaçao, n. 19, p.20-28, 2002.

SANTOS, B. de S. A gramática do tempo: para uma nova cultura política. São Paulo: Cortez, 2006.

SILVA, M. da P. Educação intercultural: a presença indígena nas escolas da cidade e a lei 11.645/2008. In: SILVA, E.; SILVA, M. da P. A temática indígena na sala de aula: reflexões para o ensino a partir da lei 11.645/2008. Recife: Ed. dos Organizadores, 2016. p.57-84

SILVA, P. B. G. e. Africanidades Brasileiras: esclarecendo significados e definindo procedimentos pedagógicos. Revista do Professor, n. 19, v. 73. Porto Alegre, jan./mar., 2003, p. 26-30.

VYGOTSKY, L. S. A formação social da mente. 2. ed. Trad. José Cipolla Neto, Luis Silveira Menna Barreto e Solange Castro Afeche. São Paulo: Martins Fontes, 1988.

\section{Como referenciar este artigo}

AMORIM, R.; CERDAS, L. Alfabetização e africanidades: experiências formativas no curso de extensão ler e escrever na escola. Revista Temas em Educação e Saúde, Araraquara, v.14 n.1 p. 41-54, jan./jun., 2018. E-ISSN: 2526-3471. DOI: 10.26673/rtes.v14.n1.2018.10632.

Submetido em: 08/11/2017

Aprovado em: 04/05/2018 